\title{
When does benevolent leadership lead to creativity? The moderating role of creative role identity and job autonomy
}

\author{
AN-CHIH WANG AND BOR-SHIUAN CHENG* \\ National Taiwan University, No. 1, Section 4, Roosevelt Road, Taipei, 10617 Taiwan, ROC
}

\begin{abstract}
Summary The present study identified creative role identity and job autonomy as two moderators that influence the relationship between benevolent leadership, a leadership style that prevails in paternalistic contexts, and creativity. Using 167 dyads of supervisor and subordinate as a sample, we found that both creative role identity and job autonomy have significant moderating effects: When each moderator is high, the positive relationship between benevolent leadership and creativity is stronger; when each moderator is low, this relationship is weaker. Our results suggest that the effect of benevolent leadership upon creativity is dependent on the coexistence of important individual and contextual factors. Copyright (C) 2009 John Wiley \& Sons, Ltd.
\end{abstract}

\section{Introduction}

Leaders enact a paternalistic role with fatherly benevolence in traditional Chinese societies (Cheng, Chou, \& Farh, 2000; Pellegrini \& Scandura, 2008). Although the greater China region is undergoing profound transitions resulting from globalization and rapid societal modernization, the construct domain of benevolent leadership has been nearly unaffected (Farh, Liang, Chou, \& Cheng, 2008). According to Farh et al. (2008), benevolent leadership can be demonstrated as a form of individualized care within a work domain, such as allowing opportunities to correct mistakes, avoiding the public embarrassment of subordinates, providing coaching and mentoring, and showing concern for subordinates' career development. It can also be expressed as a form of individualized care within a non-work domain, such as treating subordinates as family members, assisting subordinates during their personal crises, and showing holistic concern beyond professional relationships.

In the Chinese context, benevolent leadership is effective in increasing subordinates' productivity because it makes subordinates feel obligated to reciprocate and obey the leader (Farh \& Cheng, 2000; Farh, Cheng, Chou, \& Chu, 2006). Using samples collected from Chinese, Taiwanese, and other overseas Chinese enterprises, previous studies consistently revealed that benevolent leadership strongly promotes subordinates' deference to, gratitude to, and identification with the leader (e.g.,

* Correspondence to: Bor-Shiuan Cheng, Department of Psychology, National Taiwan University, No. 1, Section 4, Roosevelt Road, Taipei, 10617 Taiwan, ROC. E-mail: chengbor@ntu.edu.tw 
Cheng, Chou, Wu, Huang, \& Farh, 2004; Farh et al., 2006). Literature on paternalistic leadership also evidenced the positive effect of benevolent leadership on a variety of favorable subordinate outcomes, such as satisfaction with the leader, organizational commitment, job performance, and organizational citizenship behavior (for a review, see Farh et al., 2008).

While prior research has accumulated substantial findings regarding the effectiveness of benevolent leadership, clear prediction about the relationship between benevolent leadership and creativity cannot be made from the same theoretical base. Creativity, the production of novel and useful ideas, is crucial to organizational innovation, which is increasingly recognized as the key to organizational effectiveness (Amabile, 1988; Oldham \& Cummings, 1996). In the Chinese context, benevolent leadership arouses subordinates' feelings of obligation to their role, such as loyalty and obedience (Farh \& Cheng, 2000). Such obligation may discourage out-of-the-box thinking, which, in turn, stifles creativity (Oldham \& Cummings, 1996). However, creativity literature has strongly emphasized the positive effect of supervisory support on creativity (Gong, Huang, \& Farh, in press; Scott \& Bruce, 1994; Oldham \& Cummings, 1996; Tierney, Framer, \& Graen, 1999; Tierney \& Farmer, 2002; Shin \& Zhou, 2003). As a culture-specific form of supervisory support, benevolent leadership is also likely to cultivate a psychologically safe environment, which, in turn, boosts creativity (Tierney et al., 1999). Clearly, the potential dilemma associated with the relationship between benevolent leadership and creativity should be clarified.

One of the meaningful ways to interpret this sophisticated relationship may be to identify critical moderators that interact with benevolent leadership. The purpose of the present study, therefore, is to theorize and empirically investigate such moderating effects to provide a better understanding of the relationship between benevolent leadership and creativity within the Chinese context. In the present study, we identify both individual difference and contextual perception as moderating mechanisms. Specifically, creative role identity refers to a self-attributed meaning in reference to the role of performing creatively in the workplace (Farmer, Tierney, \& Kung-McIntyre, 2003). We posit that subordinates who exhibit a high creative role identity tend to treat benevolent leadership as an important support for their creative process, which suggests a positive moderating effect on the benevolent leadership and creativity relationship. In addition, job autonomy is defined as an individual's sense of choice in terms of work methods, pace, and effort (Hackman \& Oldham, 1980; Spector, 1986). We posit that its encouragement for creativity tends to result in a stronger link between benevolent leadership and creativity. A field investigation in Taiwan, one part of the cultural regions that value paternalism, was conducted to answer our research questions.

\section{Theory and Hypotheses}

\section{Benevolent leadership and creativity}

Benevolent leadership has been found to be prevalent in contemporary Chinese organizations (e.g., Cheng, 1995; Redding, 1990; Westwood, 1997). Max Weber (1947) argued that as modern organizations depended more on rules and the protection of individual rights, paternalistic practices would eventually become obsolete. Contrary to his prediction (and consistent with the conclusion of early behavioral management theorists, such as Munsterberg, 1913), Chinese leaders tend to be nurturing "in order to build work groups that are productive and satisfied" (Pellegrini \& Scandura, 2008, p. 567). They demonstrate individualized, holistic concern for subordinates' well-being, both personal and familial (Farh \& Cheng, 2000; Cheng et al., 2004). 
Farh and Cheng (2000) devoted much attention to the social and cultural forces underlying benevolent leadership. They concluded that benevolent leadership originates in Confucianism, which highlights mutuality in social relations. According to Confucian ethics, a ruler should be benevolent to his ministers, and, in turn, the ministers should be loyal to the ruler. Similarly, a father should be kind to his children, and, in turn, the children should show gradtitude and obeidence to their father. When each party dutifully performs his or her respective role, relational harmony is maintained (Cheng, Wang, \& Huang, 2009). As these Confucian principles are applied to the contemporary workplace, mutual obligations on the basis of duty fulfillment emerge. Leaders demonstrate benevolence in order to fulfill a role obligation specified by cultural consensus. In response to benevolent leadership, subordinates show respect and loyalty to their benevolent leader in completion of their role obligations.

From Farh and Cheng's (2000) perspective, benevolent leadership is correlated with but distinct from supportive supervision (Deci \& Ryan, 1987) and the leader-member exchange (LMX; Graen \& Uhi-Bien, 1995). Like benevolent leaders, supportive supervisors show concern for subordinates' feelings and needs, provide positive and informative feedback, and help subordinates develop necessary skills (Deci \& Ryan, 1987). However, the purpose of supportive supervision is primarily to help subordinates accomplish their workplace tasks, while benevolent leadership is demonstrated to fulfill the leader's role obligation emphasized within traditional Chinese culture. The focus of such a role obligation is on subordinates themselves rather than on their work assignments. Therefore, benevolent leadership is not restricted to the work domain. A benevolent leader also takes care of subordinates beyond professional relationships.

LMX theory is also based on notions of role making (Graen, 1976), but the roles of each party in the leader-subordinate dyad are specified by a series of role negotiation processes (Graen \& Uhi-Bien, 1995) rather than cultural traditions. That is, on the basis of social exchange and equity rules, leaders convey role expectations to subordinates and provide rewards to those who satisfy the expectations. Subordinates also uphold the role expectations of their leaders; they may embrace, renegotiate, or reject roles prescribed by their leaders. Over time, each party brings different kinds of exchange resources to the dyadic relationship. However, the role of a benevolent leader is not specified by role negotiation processes, but rather cultural consensus based on Confucianism. Moreover, benevolent leadership is not necessarily a form of exchange currency. Even though a leader needs nothing from his or her subordinates, he or she may still demonstrate benevolent behavior in order to fulfill the role obligation specified by Confucian ethics.

Prior research considered supportive supervision an effective leading strategy to develop subordinates' creativity (Oldham \& Cummings, 1996). LMX literature also reported that one of leaders' goals in maintaining high-quality relationships with subordinates is to elicit creative performances in return (Liden \& Graen, 1980; Graen \& Scandura, 1987). In contrast to those clear objectives, the original aim of benevolent leadership is more remote from improving subordinates' creativity. As traditional Chinese leaders showed benevolence, they did not expect to receive subordinates' creativity in return. However, given the prevalence of benevolent leadership and the importance of creativity in contemporary organizations, it is necessary to understand how this leadership style affects creativity.

Benevolent leadership greatly contributes to subordinates' loyalty, obedience, and submission, which might facilitate a controlling relationship that inhibits creativity (Oldham \& Cummings, 1996). That is, benevolent leadership is intended to arouse subordinates' feelings of obligation to their prescribed role expectations, such as loyalty and obedience (Farh \& Cheng, 2000). Primed by such role obligation, subordinates tend to follow their leader's instructions without examining the underlying status quo and coming up with alternative problem-solving strategies. As a result, subordinates are less likely to produce creative outcomes in the workplace. 
However, this type of leadership may also set the stage for creativity in a number of ways. For example, benevolent leadership strongly signals that a leader approves of his or her follower's role as both an exemplary subordinate and as a valuable person (Farh \& Cheng, 2000). Subordinates who perceive such approval tend to experience a strong sense of gratitude (Cheng et al., 2004), which is conducive to a level of comfort and interpersonal trust necessary for creativity (Mumford \& Gustafson, 1988). Additionally, subordinates who perceive high levels of benevolent leadership also receive more task-related resources and recognition (Farh \& Cheng, 2000; Farh et al., 2008). These factors suggest a leader's receptiveness to and support for creative work (Amabile, 1988).

Taken together, prior research suggests a complex relationship between benevolent leadership and creativity. Creativity researchers have long suggested that personal, job, and supervisory variables interact to influence creativity (Woodman, Sawyer, \& Griffin, 1993; Amabile, 1996; Oldham \& Cummings, 1996; Tierney et al., 1999). Hence, it is likely that important individual differences or contextual factors alter how subordinates interpret their leader's benevolence and, in turn, moderate the relationship between benevolent leadership and creativity. We identify creative role identity and job autonomy as such moderators.

\section{The moderating role of creative role identity}

A role identity refers to a self-view regarding a specific role (Burke \& Tully, 1977; Burke, 1991). According to role identity theories, role-consistent behaviors reconcile the self-views of an individual with the perceived views that others hold of him or her, thereby verifying, supporting, and validating that individual's role identity (Riley \& Burke, 1995). Thus, individuals tend to behave in accordance with their role identities because no longer fulfilling a role may result in considerable social and personal costs (McCall \& Simmons, 1978). Similarly, if an individual with high levels of a role identity anticipates negative responses to his or her role-consistent behaviors, he or she tends to avoid such behaviors in order to protect his or her self-view (McCall \& Simmons, 1978; Burke, 1991). Farmer et al. (2003) thus argued that some employees view personal creativity as a central part of "who they are" and developed a measure for this construct and tested a model of creative role identity and creativity.

From the role identity perspective, we hypothesize that creative role identity moderates the relationship between benevolent leadership and creativity. Strong creative role identity should ease the potential dilemma associated with the link between benevolent leadership and creativity: Although benevolent leadership reminds subordinates of their role to show loyalty and obedience (Farh \& Cheng, 2000), they are inclined to fulfill their role obligations in a way that does not contradict their creative roles. Specifically, subordinates holding a strong creative role identity are highly sensitive to contextual supports for (or threats to) their creative roles (Farmer et al., 2003) so that they tend to treat high levels of benevolent leadership as an important support for their creative action. They enjoy utilizing their leader's benevolence to perform more creatively because doing so fulfills their critical need for selfverification (McCall \& Simmons, 1978; Riley \& Burke, 1995). With such strong creative role identity, they also respond drastically to the lack of benevolent leadership. Low levels of benevolence induce a serious threat to their creative role identity, as creative actions may receive little support from their leaders. To prevent their self-views from damage, they tend to opt out of creative actions (McCall \& Simmons, 1978; Burke, 1991; Farmer et al., 2003). Thus, a strong, positive relationship is expected between benevolent leadership and the creativity of subordinates high in creative role identity.

In contrast, as being a creative employee is not a meaningful part of "who they are" (Farmer et al., 2003), subordinates low in creative role identity are insensitive to contextual supports for (or threats to) their creative endeavors. Low levels of benevolent leadership have little effect on their creative production; they do not deliberately avoid opportunities to perform creatively when benevolent 
leadership is low (McCall \& Simmons, 1978; Farmer et al., 2003). High levels of benevolent leadership, on the other hand, remind them of their role obligation specified in cultural traditions much more than providing useful resources for their creative actions. Hence, benevolent leadership mainly generates indebtedness, loyalty, and obedience that may facilitate a controlling supervisor-subordinate relationship. A controlling supervisory style discourages out-of-the-box thinking, enhances satisfaction with the status quo, and, in turn, has a harmful effect on creativity (Oldham \& Cummings, 1996). Therefore, for subordinates low in creative role identity, a negative relationship between benevolent leadership and creativity is expected.

Hypothesis 1: Creative role identity moderates the relationship between benevolent leadership and creativity.

Hypothesis 1(a): High levels of creative role identity strengthen the positive relationship between benevolent leadership and creativity.

Hypothesis 1(b): Low levels of creative role identity weaken this relationship so that benevolent relationship is negatively related to creativity.

\section{The moderating role of job autonomy}

Job autonomy refers to the extent to which an individual can determine his or her methods, pace, and effort to accomplish work tasks (Hackman \& Oldham, 1980; Spector, 1986). Autonomous jobs are expected to encourage higher levels of creativity than controlled jobs because job autonomy makes employees feel self-determined and free from external controls or constraints (Deci, Connell, \& Ryan, 1989; Spreitzer, 1995). That is, autonomous job design promotes new and useful combinations among multiple dimensions of a work task, whereas controlled jobs are designed to hinder such opportunities (Oldham \& Cummings, 1996). Employees high in job autonomy are, thus, more likely to engage in risk taking, alternative thinking, and problem solving, all of which are expected to foster creativity (Amabile, 1988; Oldham \& Cummings, 1996; Tierney \& Farmer, 2002).

We, therefore, hypothesize that job autonomy moderates the relationship between benevolent leadership and creativity. When job autonomy is high, the potential dilemma associated with the benevolent leadership-creativity link is unlikely to occur. High levels of job autonomy indicate considerable latitude to determine one's work activities as well as high support for creativity in one's job (Hackman \& Oldham, 1980; Amabile, Conti, Coon, Lazenby, \& Herron, 1996; Oldham \& Cummings, 1996; Spector, 1986). While benevolent leadership enhances subordinates' sense of responsibility toward role obligations (Farh \& Cheng, 2000), the autonomous job design allows subordinates to fulfill the obligations in creative ways. Benevolent leadership, thus, tends to create a psychologically safe envorionment for creative endeavors. While low levels of benevolent leadership decrease the usable resources for creativity, high levels of benevolent leadership provide a context of comfort, trust, and receptiveness. Therefore, there is a strong, positive relationship between benevolent leadership and creativity.

On the contrary, low levels of job autonomy suggest that subordinates have little choice in terms of their work tasks and strategies for fulfilling those tasks (Hackman \& Oldham, 1980; Spector, 1986; Amabile et al., 1996; Oldham \& Cummings, 1996). Under this condition, the job design does not encourage creativity; subordinates tend to interpret benevolent leadership mostly from the traditional perspective. In the Chinese cultural context, benevolent leadership is intended to arouse subordinates' conformity and loyalty (Farh \& Cheng, 2000). These reponses may discourage creative actions, such as trying alternatives, challenging authority, and questioning underlying hypotheses. While low levels of 
benevolent leadership have little effect on creativity, high levels of benevolent leadership are likely to stifle creativity when subordinates have little job autonomy. Thus, we hypothesize a negative relationship between benevolent leadership and creativity when job autonomy is low.

Hypothesis 2: Job autonomy moderates the relationship between benevolent leadership and creativity.

Hypothesis 2(a): High levels of job autonomy strengthen the positive relationship between benevolent leadership and creativity.

Hypothesis 2(b): Low levels of job autonomy weaken this relationship so that benevolent relationship is negatively related to creativity.

\section{Methods}

\section{Research context, sample, and procedure}

In this study, we surveyed a group of research and development engineers and their supervisors in seven high-technology manufacturing companies in Taiwan. We contacted human resources managers at each company to elicit their help in distributing matching questionnaires to randomly identified supervisors and two of their direct reports. Subordinates provided information about their creative role identity, job autonomy, perceptions of their supervisors, and demographics. On separate questionnaires, their corresponding supervisors rated the subordinates' creativity in the workplace. After completing the surveys, each respondent sealed his or her questionnaire in an envelope and returned it to the authors by mail.

The matching surveys were initially distributed to 220 dyads. We received 167 completed and usable matching pairs, which represented an overall response rate of $76 \%$. The average age of the responding subordinates was 30.89 years (s.d. $=4.76)$, with an average company tenure of 3.61 years $($ s.d. $=3.17$ ). The majority of the sample was male (63\%) and well educated (75\% held bachelor's or higher degrees). The sampled supervisors were primarily male (72\%) and highly educated (84\% held bachelor's or higher degrees) as well. Their mean age was 36.49 years $($ s.d. $=4.73)$ and the mean coporate tenure was 6.59 years $($ s.d. $=4.30)$.

\section{Measures}

Following the translation and back-translation procedure suggested by Brislin (1986), we created Chinese versions of measures for creative role identity, job autonomy, and creativity. Because Chinese respondents tend to choose the mid-point on a Likert scale (Yang \& Chiu, 1987), we converted the original 5- or 7-point scales into 6-point scales to eliminate a possible mid-point.

\section{Creativity}

We measured subordinates' creativity using Zhou and George's (2001) 13-item scale $(\alpha=.97)$. On a 6-point scale ranging from 1, "very uncharacteristic," to 6, "very characteristic," supervisors rated how characteristic each of 13 behaviors was for each employee. Sample items is "comes up with new and practical ideas to improve performance." Because our 167 dyads were not unique (most 
supervisors rated two subordinates' creativity), we calculated an intraclass correlation coefficient (ICC1) to determine to what degree there is a supervisor effect (e.g., benevolent supervisors rate everyone more highly on creativity) in the creativity ratings. We obtained an ICC1 of .20 and a significant $F$-value from the ANOVA $(21.51, p<.01)$, indicating that there may be a supervisor effect. Thus, we employed hierarchical linear modeling (HLM) to control for this effect in the present study.

\section{Benevolent leadership}

Eleven items of Cheng et al.'s (2000) benevolent leadership scale were used to test leader benevolence $(\alpha=.86)$. On a 6-point scale that ranges from 1, "not at all," to 6, "frequently," the employees reported the frequency of perceiving their supervisors' benevolent behavior. Sample items include "my supervisor tries to understand the cause when I do not perform well," and "my supervisor will help me when I am in an emergency."

The nested structure of our data suggests that methodologically, it is possible to treat benevolent leadership as a group-level construct (i.e., to aggregate benevolent leadership scores reported by subordinates under the same leader). However, doing so introduces a mismatch between theory and analysis. That is, while we position benevolent leadership as the predictor of creativity, using benevolent leadership as a group-level construct suggests a cross-level moderating role of benevolent leadership in the individual-level relationship between creative role identity (or job autonomy) and creativity. More importantly, Farh and Cheng (2000) argued that under Chinese settings, where relationalism is highly valued, the treatment of benevolent leadership is likely to differ across subordinates. This argument suggests the appropriateness of investigating benevolent leadership at the individual leavel. We, thus, treated benevolent leadership as an individual-level variable.

\section{Creative role identity}

Farmer et al.'s (2003) three-item scale was used to measure creative role identity $(\alpha=.81)$. On a 6-point scale that ranges from 1, "strongly disagree," to 6, "strongly agree," subordinates evaluated the extent to which the role of creative employees had been incorporated into their self-identity. Sampled item is "To be a creative employee is an important part of my identity."

\section{Job autonomy}

Spreitzer's (1995) three-item autonomy/self-determination scale was used to measure job autonomy $(\alpha=.86)$. On a 6-point scale ranging from 1, "strongly disagree," to 6, "strongly agree," employees indicated the extent to which each statement described how they felt about their work. Sample item is "I have significant autonomy in determining how I do my job."

\section{Control variables}

We included two controls in the statistical analyses. First, we included educational level $(1=$ "high school," 2 = "institute of technology," 3 = "bachelor's," and $4=$ "master's") to control for its potential impact on creativity via task-related knowledge and expertise (Amabile, 1988). Second, the length of the supervisor-subordinate relationship was controlled because it may affect supervisors' rating on direct reports.

\section{Results}

We first performed a set of confirmatory factor analyses to examine the construct distinctiveness of benevolent leadership, creative role identity, job autonomy, and creativity. Because of the large number 
of items that were used to measure benevolent leadership and creativity, three manifest indicators for each construct were created by randomly assigning items to composites. Therefore, 12 indicators were used to conduct our confirmatory factor analyses. As shown in Table 1, the hypothesized four-factor model fit the data well $\left(\chi^{2}=80.36, \mathrm{df}=48, \mathrm{RMSEA}=.064, \mathrm{CFI}=.97, \mathrm{IFI}=.97\right)$. The loadings of the subscales on their respective constructs were each significant. Following Williams and Anderson (1994), we then collapsed some of the factors to form alternative models. Results reported in Table 1 showed that none of these models obtained acceptable fit indices and that all chi-squared differences between baseline and alternative models were significant. Hence, the above results provided evidence for the construct distinctiveness.

Means, standard deviations, and correlations for all variables appear in Table 2. Inconsistent with our argument that benevolent leadership is an ambivelant predictor of creativity, there was a positive relationship between benevolent leadership and creativity $(r=.33, p<.01)$. Supporting the prior literature on creativity (Oldham and Cummings, 1996; Oldham \& Cummings, 1996Farmer et al., 2003), creative role identity and job autonomy were positively related to creativity as well $(r=.20$ and .31 , respectively, $p<.01$ ). A positive correlation for the relationship between benevolent leadership and length of supervisor-subordinate relationship was found $(r=.17, p<.05)$, suggesting that leaders tend to express more benevolence to subordinates who have spent a long time with them.

The HLM techique, which enables statistical control for the supervisor effect on outcome variable, was applied to test our hypotheses. All studied variables were centered before entering regression models. Table 3 presents the results. Model 1 examined the moderating effect of creative role identity on the relationship between benevolent leadership and creativity. After entering controls, benevolent leadership, and creative role identity, the benevolent leadership $\times$ creative role identity interaction term

Table 1. Comparison of measurement models for variables collected from subordinates' surveys

\begin{tabular}{|c|c|c|c|c|c|c|c|}
\hline Model & $\chi^{2}$ & df & $\Delta \chi^{2}$ & $\Delta \mathrm{df}$ & CFI & IFI & RMSEA \\
\hline $\begin{array}{l}\text { Null model (All the indicators are } \\
\text { independent.) }\end{array}$ & 1311.72 & 66 & & & & & \\
\hline Baseline model (Four factors.) & 80.36 & 48 & - & - & .97 & .97 & .064 \\
\hline $\begin{array}{l}\text { Model } 1 \\
\text { (Three factors; creative role identity } \\
\text { and job autonomy were combined into } \\
\text { one factor.) }\end{array}$ & 121.21 & 51 & $40.85^{* *}$ & 3 & .94 & .94 & .091 \\
\hline $\begin{array}{l}\text { Model } 2 \\
\text { (Three factors; creative role identity } \\
\text { and benevolent leadership were combined } \\
\text { into one factor.) }\end{array}$ & 133.03 & 51 & $52.67^{* *}$ & 3 & .93 & .93 & .098 \\
\hline $\begin{array}{l}\text { Model } 3 \\
\text { (Three factors; benevolent leadership } \\
\text { and job autonomy were combined into } \\
\text { one factor.) }\end{array}$ & 200.71 & 51 & $120.35^{* *}$ & 3 & .88 & .88 & .133 \\
\hline $\begin{array}{l}\text { Model } 4 \\
\text { (Two factors; benevolent leadership, } \\
\text { creative role identity, and job autonomy } \\
\text { were combined into one factor.) }\end{array}$ & 236.11 & 53 & $155.75^{* *}$ & 5 & .85 & .85 & .144 \\
\hline
\end{tabular}

${ }^{* *} p<.01$. 
Table 2. Means standard deviations, and correlations of the variables

\begin{tabular}{lcccccccc}
\hline Variables & $N$ & Means & s.d. & 1 & 2 & 3 & 4 & 5 \\
\hline 1. Creativity & 163 & 4.14 & 0.82 & $(.97)$ & & & & \\
2. Benevolent leadership & 167 & 3.88 & 0.65 & $.33^{* *}$ & $(.86)$ & & \\
3. Creative role identity & 166 & 4.56 & 0.81 & $.20^{* *}$ & $.34^{* *}$ & $(.81)$ & $.41^{* *}$ & $(.86)$ \\
4. Job autonomy & 166 & 4.23 & 0.89 & $.31^{* *}$ & $.36^{* *}$ & .05 & .00 & .09 \\
5. Education level & 167 & 3.03 & 0.78 & .05 & -.07 & -.05 & $.15^{*}$ \\
6. Length of relationship & 165 & 2.19 & 1.88 & .11 & $.17^{*}$ & .11 & .09 \\
\hline
\end{tabular}

Note. Internal consistency reliabilities are given in parentheses.

${ }^{*} p<.05 ;{ }^{* *} p<.01$.

was entered into Model 1 . As shown, we obtained a significant benevolent leadership $\times$ creative role identity interaction $(\gamma=.38, p<.01)$. Figure 1 is a graphic representation of this interaction. In Figure 1, the relationship between benevolent leadership and creativity was plotted at different levels of creative role identity (i.e., one standard deviation above/below the mean of creative role identity; see Aiken \& West, 1991). As shown, when creative role identity was high, there is a strong, positive relationship between benevolent leadership and creativity (simple slope estimate $=.62, p<.01$ ). Hypothesis 1(a) was, thus, fully supported. When creative role identity was low, this relationship weakens to an insignificant level (simple slope estimate $=.01, p>.05$ ). Inconsistent with Hypothesis 1(b), however, the slope estimate was near zero rather than negative. Hypothesis 1(b) was, hence, not

Table 3. Results for hypothesis testing

\begin{tabular}{|c|c|c|c|c|c|}
\hline \multirow[b]{2}{*}{ Variables } & & \multicolumn{4}{|c|}{ Creativity } \\
\hline & & Model 1 & Model 2 & Model 3 & Model 4 \\
\hline Intercept & $\gamma_{00}$ & $4.13^{* *}$ & $4.12^{* *}$ & $4.13^{* *}$ & $4.13^{\text {** }}$ \\
\hline \multicolumn{6}{|l|}{ Controls: } \\
\hline Education level (EDU) & $\gamma_{10}$ & .14 & .13 & .13 & .13 \\
\hline Length of relationship (LEN) & $\gamma_{20}$ & .02 & .01 & .01 & .00 \\
\hline \multicolumn{6}{|l|}{ Main effects: } \\
\hline Benevolent leadership (BEN) & $\gamma_{30}$ & $.32^{* *}$ & $.28^{* *}$ & $.26^{* *}$ & $.21^{*}$ \\
\hline \multicolumn{6}{|l|}{ Moderators: } \\
\hline Creative role identity (CRI) & $\gamma_{40}$ & .13 & & .05 & .05 \\
\hline Job autonomy (AUT) & $\gamma_{50}$ & & $.25^{* *}$ & $.23^{* *}$ & $.20^{* *}$ \\
\hline \multicolumn{6}{|l|}{ Interactions: } \\
\hline $\mathrm{BEN} \times \mathrm{CRI}$ & $\gamma_{60}$ & $.38^{* *}$ & & .21 & .17 \\
\hline $\mathrm{BEN} \times \mathrm{AUT}$ & $\gamma_{70}$ & & $.39^{* *}$ & $.27^{*}$ & $.24^{*}$ \\
\hline $\mathrm{CRI} \times \mathrm{AUT}$ & $\gamma_{80}$ & & & & .10 \\
\hline $\mathrm{BEN} \times \mathrm{CRI} \times \mathrm{AUT}$ & $\gamma_{90}$ & & & & .12 \\
\hline
\end{tabular}

Note. Data including missing values were deleted before conducting analyses.

$N$ for hierarchical linear modeling $=87$ supervisors and 159 subordinates.

Level 1: Creativity $=\beta_{0}+\beta_{1} \times \mathrm{EDU}+\beta_{2} \times \mathrm{LEN}+\beta_{3} \times \mathrm{BL}+\beta_{4} \times \mathrm{CRI}+\beta_{5} \times \mathrm{AUT}+\beta_{6} \times(\mathrm{BEN} \times \mathrm{CRI})+\beta_{7} \times(\mathrm{BEN} \times \mathrm{AUT})+$

$\beta_{8} \times(\mathrm{CRI} \times \mathrm{AUT})+\beta_{9} \times(\mathrm{BEN} \times \mathrm{CRI} \times \mathrm{AUT})+r$.

Level 2: $\beta_{n}=\gamma_{n 0}+u_{0 n} . n=1-9$.

${ }^{*} p<.05 ;{ }^{* *} p<.01$. 


\section{Creativity}

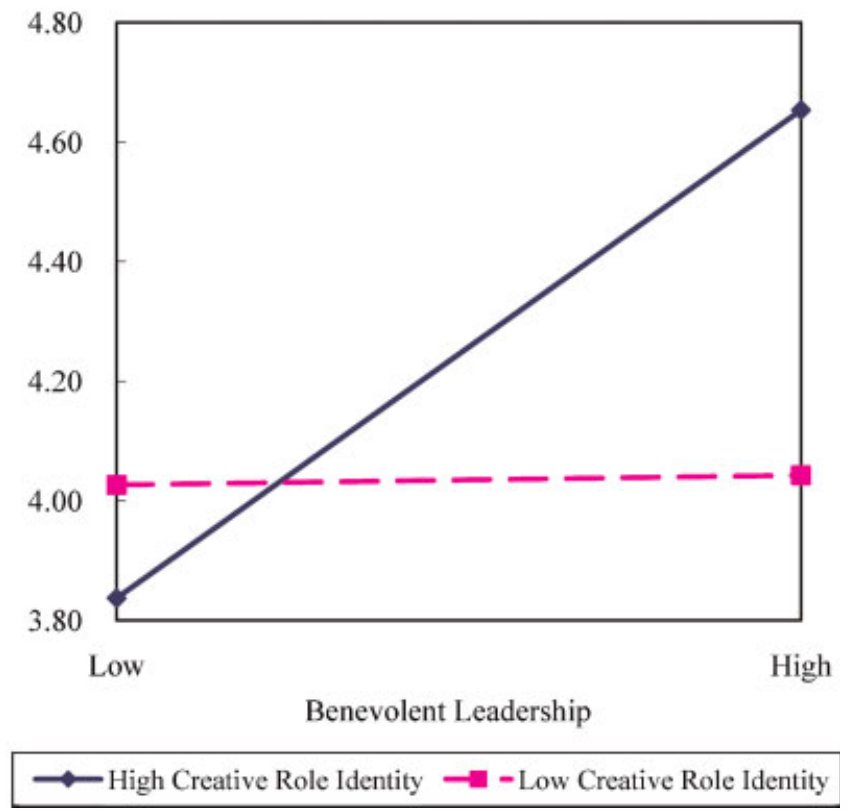

Figure 1 . The benevolent leadership $\times$ creative role identity interactive effect for creativity

supported. Taken together, we found that the positive effect of benevolent leadership was dependent on the coexistence of high creative role identity.

In Model 2, the benevolent leadership $\times$ job autonomy interaction term was entered into the model after two controls and two main effect terms. We also found a significant interactive effect between benevolent leadership and job autonomy $(\gamma=.39, p<.01)$. We plotted this interaction in Figure 2 following the same procedure used in Figure 1. Supporting Hypothesis 2(a), Figure 2 revealed that when job autonomy was high, a strong, positive relationship between benevolent leadership and creativity is found (simple slope estimate $=.63, p<.01$ ). When job autonomy was low, the slope for the benevolent leadership_creativity relationship is negative but insignificant $(-.07, p>.05)$. Hypothesis 2(b) was, therefore, not supported. Taken together, the presence of high job autonomy was essential to the positive effect of benevolent leadership on creativity.

We then examined both moderating effects in the same HLM model (Model 3) to compare the two moderating effects observed in Models 1 and 2. Controls and three main effect terms (benevolent leadership, creative role identity, and job autonomy) were entered first. The benevolent leadership $\times$ creative role identity interaction term and the benevolent leadership $\times$ job autonomy interaction term were then added to the model. According to Farh, Hackett, and Liang (2007), if one interaction term was significant while the other in the same regression model was not, the former was the stronger moderator. As shown in Model 3, while the former interaction became insignificant $(\gamma=.21, p>.05)$, the latter remained significant $(\gamma=.27, p<.05)$. Therefore, our results from Model 3 suggest that job autonomy is a stronger moderator than creative role identity for the relationship between benevolent leadership and creativity.

Finally, in Model 4, the three-way interaction term was added into the model after all main effect and two-way interaction terms were entered to check whether there was a higher-order interaction among benevolent leadership and the two moderators. As shown in Table 3, we obtained an insignificant 
Creativity

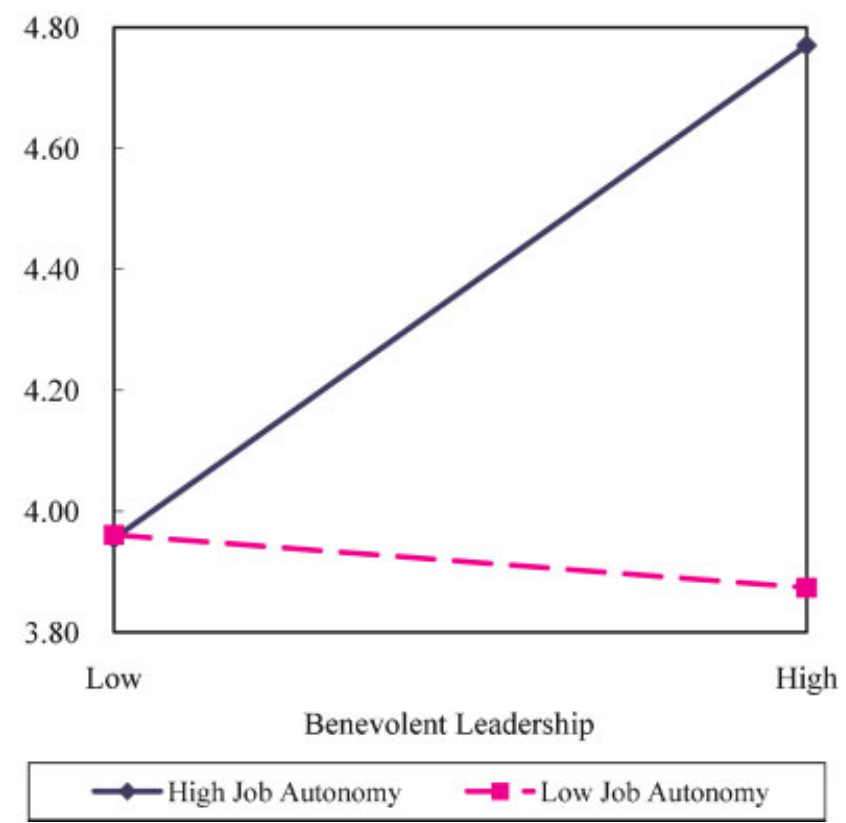

Figure 2. The benevolent leadership $\times$ job autonomy interactive effect for creativity

coefficient for the three-way interaction term $(\gamma=.12, p>.05)$. Again, indicating that job autonomy was a stronger moderator than creative role identity, the benevolent leadership $\times$ job autonomy interaction term was the only significant interaction $(\gamma=.24, p<.05)$ in Model 4 . The above results indicated that higher-order interaction may not exist among benevolent leadership, creative role identity, and job autonomy.

\section{Discussion}

While never documented in the prior literature, results of the present study suggest that the relationship between benevolent leadership and creativity is dependent on two moderators: creative role identity and job autonomy. This relationship is positive either when creative role identity or job autonomy is high. When subordinates hold low levels of creative role identity or do not have choice in work methods, pace, and effort, benevolent leadership has little effect on creativity. Moreover, in contrast to creative role identity, job autonomy is the stronger moderator.

\section{Theoretical contributions}

The present study suggests that there is a complex relationship between benevolent leadership and creativity, the forms of which vary with both individual (i.e., creative role identity) and contextual (i.e., 
job autonomy) factors. Our findings are consistent with the interactionist perspective of creativity (Woodman et al., 1993; Oldham \& Cummings, 1996), which argues that creativity is produced by the joint effect of individual and contextual factors. Many studies have evidenced that supervisor factors interact with creative self-views or job contexts to maximize their creativity levels (e.g., Oldham \& Cummings, 1996; Tierney et al., 1999; Zhou \& George, 2001; Madjar, Oldham, \& Pratt, 2002; Shin \& Zhou, 2003; Shin \& Zhou, 2007). Similarly, in order to obtain a comprehensive understanding of the connection between benevolent leadership and creativity, researchers must take into account both individual differences and contextual factors that moderate this relationship.

According to our findings, in addition to task-related supervisory support as an exchange currency for subordinates' creativity (Oldham \& Cummings, 1996; Tierney et al., 1999), benevolent leadership play an important role in the process of creativity production. In general, benevolent leadership is meant to elicit role obligations specified by cultural traditions (Farh \& Cheng, 2000) rather than to promote creativity in the workplace. We, however, suggest that benevolent leadership has a favorable "side effect" when subordinates consider it a support for a psychologically safe environment. While prior research argued that in the Chinese context, exposure to Western cultures contributes to the generation of creative ideas (Farmer et al., 2003), we point out the critical role of Chinese cultural constructs.

Given that benevolent leadership is embedded in a set of cultural and organizational conditions (Farh \& Cheng, 2000), the effects of benevolent leadership are not expected to be consistent across all situations. However, prior literature paid little attention to this important issue (but see Farh et al., 2006, for an exception). Farh et al. (2008), therefore, called for more systematic investigations on how situational factors may amplify or neutralize the effects of benevolent leadership on subordinate outcomes. The present study filled this lacuna via pointing out two additional situational factors (creative role identity and job autonomy) that moderate the link between benevolent leadership and its outcome (creativity). Our results support the argument that the effectiveness of benevolent leadership is situational (Farh \& Cheng, 2000; Farh et al., 2008) and recommend more future research examining when benevolent leadership makes a difference in the workplace.

Contrary to our prediction, we did not find a negative relationship between benevolent leadership and creativity when creative role identity or job autonomy is low. We propose two potential explanations for this unexpected finding. First, perhaps this finding actually reflects the nature of workplace creativity. Workplace creativity often takes time and hard work (Shalley, Zhou, \& Oldham, 2004). While gratitude and loyalty to supervisors resulting from benevolent leadership do not encourage the re-examination of the status quo, these responses may enhance goal-level persistence, which prior literature considered conducive to creativity (Bandura, 1997; Shalley et al., 2004; Tierney \& Farmer, 2002). Second, this finding may result from the limitation of our sampling strategy. Our results are based on a sample of research and development engineers, who are likely to hold high creative role identity or have high job autonomy. Future research should used other samples to check whether our results were subject to the restriction of range.

Additionally, the results of the present study showed that job autonomy is a stronger moderator than creative role identity for the relationship between benevolent leadership and creativity. Again, this finding might reveal that in our data, creative role identity suffers more from the restriction of range than job autonomy. Notwithstanding such a possibility, this finding may still suggest that the positive link of benevolent leadership with creativity depends more on contextual factors than on individual differences. This may be attributed to the "powerful situation" hypothesis, which argues that individual differences tend to have little effect on behavior in powerful situations, where the context primarily guides behavior (Gatewood \& Field, 2001). Although prior literature has long recognized the importance of the interactionist perspective of creativity (Woodman et al., 1993; Oldham \& Cummings, 1996), few studies have empirically compared the moderating effect of individual differences and that 
of contextual factors. This comparison, such as we did in the present study, may hold promise in terms of advancing our knowledge of organizational creativity.

\section{Limitations}

Although our cross-sectional design does not compromise our examination of moderating effects, the possibility of reverse causality might exist insofar as high creativity levels lead to more benevolent leadership. Future research should apply a longitudinal research design or controlled field experiment to control for reciprocal causality. Moreover, in the present study, we only sampled industries that highly value creativity. More effort is needed to test the generalizability of our results across industries. The generalization of our results across cultures also needs to be examined further. In the Chinese context, benevolent leadership is rooted in Confucianism (Farh \& Cheng, 2000). Can the effects we observed in the present study be generalized to non-Chinese contexts that also value paternalism, such as in Eastern European, Middle Eastern, and South American settings (Aycan et al., 2000; Farh et al., 2006), or even to cultural contexts that do not value paternalism? It is necessary to replicate our findings outside of the greater China region. Also, our study would be stronger if we had controlled other leadership construct (e.g., LMX quality) to show the incremental validity of benevolent leadership. Finally, while we cannot completely exclude potential same-source bias, factor analyses have extensively supported the construct distinctiveness among the studied variables.

\section{Practical implications}

Organizations in the Chinese context are typically hierarchical, with most of the power retained in the peak of this hierarchy (Silin, 1976; Redding, 1990; Westwood \& Chan, 1992). In such a hierarchical structure, benevolent leadership depicts the ways in which a Chinese leader follows Confucian ethics to demonstrate individualized benevolence that evokes followers' gratitude, loyalty, and obedience (Farh \& Cheng, 2000). The present study suggests that in addition to its original purpose, benevolent leadership have a new meaning in relation to creativity. When benevolent leadership is combined with either creative role identity or job autonomy, both of which seem to be uncommon in traditional Chinese settings but increasingly considered important today, it has great potential to foster creative actions in the workplace. Therefore, in contemporary organizations, where creativity is increasingly valued, benevolent leadership does not become obsolete; it effectively adapts itself to the everchanging business environment.

According to our findings, organizations that have a traditional paternalistic culture, as do many companies or state-owned enterprises in inland cities of the People's Republic of China (Zhang, Song, Hackett, \& Bycio, 2006), can fully utilize benevolent leadership to develop their creative competitiveness in the globalized market. To promote creativity, we recommend that these organizations simultaneously implement autonomous work structures or recruit employees who consider creativity as the central part of their self-view in order to accompany their benevolent leadership practices. On the other hand, organizations facing great challenges to traditional paternalistic values from Westernized institutionalization, as do companies in Hong Kong, Taiwan, and coastal regions of the People's Republic of China, should think twice before their supervisors forgo benevolent leadership as an effective leading strategy. Doing so would waste an opportunity to further improve creativity. 


\section{Acknowledgements}

The authors acknowledge Kerrie Unsworth and three anonymous reviewers for their insightful comments. This research was supported by National Science Council, Executive Yuan, Taiwan (NSC96-2752-H-002-003-PAE).

\section{Author biographies}

An-Chih (Andrew) Wang is a doctoral student in the Department of Psychology at National Taiwan University. His research interests include leadership in the Chinese context, cultural values and organizational behavior, and creativity in the workplace. His previous work appeared in journals such as Human Relations and Management and Organization Review.

Bor-Shiuan Cheng is the Distinguished Professor of Psychology at National Taiwan University, where he earned his PhD degree in 1985. He is the Editor of Indigenous Psychological Research in Chinese Societies and the Associate Editor of the Asian Journal of Social Psychology. His research focuses on the impact of Chinese culture on organizational behavior and the indigenous understanding of leadership processes in the Chinese context.

\section{References}

Aiken, L. S., \& West, S. G. (1991). Multiple regression: Testing and interpreting interactions. Newbury Park, CA: Sage.

Amabile, T. M. (1988). A model of creativity and innovation in organizations. In B. M. Staw, \& L. L. Cummings (Eds.), Research in organizational behavior (Vol. 10, pp. 123-167). Greenwich, CT: JAI Press.

Amabile, T. M. (1996). Creativity in context. Boulder, CO: Westview Press.

Amabile, T. M., Conti, R., Coon, H., Lazenby, J., \& Herron, M. (1996). Assessing the work environment for creativity. Academy of Management Journal, 39, 1154-1184.

Aycan, Z., Kanungo, R. N., Mendonca, M., Yu, K., Deller, J., Stahl, G., et al. (2000). Impact of culture on human resource management practices: A 10-country comparison. Applied Psychology: An International Review, 49, $192-221$.

Bandura, A. (1997). Self-efficacy: The exercise of control. New York: Freeman.

Brislin, R. W. (1986). The wording and translation of research instruments. In W. J. Looner, \& J. W. Berry (Eds.), Field methods in cross-cultural research (pp. 137-164). Beverly Hills, CA: Sage.

Burke, P. J. (1991). Identity processes and social distress. American Sociological Review, 56, 836-849.

Burke, P. J., \& Tully, J. C. (1977). The measurement of role identity. Social Forces, 55, 881-897.

Cheng, B. S. (1995). Paternalistic authority and leadership: A case study of a Taiwanese CEO. Bulletin of the Institute of Ethnology Academic Sinica, 79, 119-173 (in Chinese).

Cheng, B. S., Chou, L. F., \& Farh, J. L. (2000). A triad model of paternalistic leadership: The constructs and measurement. Indigenous Psychological Research in Chinese Societies, 14, 3-64. (in Chinese).

Cheng, B. S., Chou, L. F., Wu, T. Y., Huang, M. P., \& Farh, J. L. (2004). Paternalistic leadership and subordinate responses: Establishing a leadership model in Chinese organizations. Asian Journal of Social Psychology, 7, 89117.

Cheng, B. S., Wang, A. C., \& Huang, M. P. (2009). The road more popular versus the road less traveled: An insider's perspective of advancing Chinese management research. Management and Organization Review, 5 , 91-105. 
Deci, E. L., Connell, J. P., \& Ryan, R. M. (1989). Self-determination in a work organization. Journal of Applied Psychology, 74, 580-590.

Deci, E. L., \& Ryan, R. M. (1987). The support of autonomy and the control of behavior. Journal of Personality and Social Psychology, 53, 1024-1037.

Farh, J. L., \& Cheng, B. S. (2000). A cultural analysis of paternalistic leadership in Chinese organizations. In J. T. Li, A. S. Tsui, \& E. Weldon (Eds.), Management and organizations in the Chinese context (pp. 85-127). London: Macmillan.

Farh, J. L., Cheng, B. S., Chou, L. F., \& Chu, X. P. (2006). Authority and benevolence: Employees' responses to paternalistic leadership in China. In A. S. Tsui, Y. Bian, \& L. Cheng (Eds.), China's domestic private firms: Multidisciplinary perspectives on management and performance (pp. 230-260). New York. Sharpe.

Farh, J. L., Hackett, R. D., \& Liang, J. (2007). Individual-level cultural values as moderators of perceived organizational support-employee outcomes relationships in China: Comparing the effects of power distance and traditionality. Academy of Management Journal, 50, 715-729.

Farh, J. L., Liang, J., Chou, L. F., \& Cheng, B. S. (2008). Paternalistic leadership in Chinese organizations: Research progress and future research directions. In C. C. Chen, \& Y. T. Lee (Eds.), Business leadership in China: Philosophies, theories, and practices (pp. 171-205). Cambridge, UK: Cambridge University Press.

Farmer, S. M., Tierney, P., \& Kung-McIntyre, K. (2003). Employee creativity in Taiwan: An application of role identity theory. Academy of Management Journal, 46, 618-630.

Gatewood, R. D., \& Field, H. S. (2001). Human resource selection (5th ed.). Orlando, FL: Dryden Press.

Gong, Y., Huang, J. C., \& Farh, J. L. (2009). Employee learning orientation, transformational leadership, and employee creativity: The mediating role of employee creative self-efficacy. Academy of Management Journal, 52. [Accessed on: http://journals.aomonline.org/inpress/main.asp?p_id=1]

Graen, G. B. (1976). Role making processes within complex organization. In M. D. Dunnette (Ed.), Handbook of industrial and organizational psychology (pp. 1201-1245). Chicago: Rand-McNally.

Graen, G. B., \& Scandura, T. A. (1987). Toward a psychology of dyadic organizing. In L. L. Cummings, \& B. M. Staw (Eds.), Research in organizational behavior (Vol. 9, pp. 175-208). Greenwich, CT: JAI Press.

Graen, G. B., \& Uhi-Bien, M. (1995). Development of leader-member exchange (LMX) theory of leadership over 25 years: Applying a multi-level multi-domain perspective. Leadership Quarterly, 6, 219-247.

Hackman, J. R., \& Oldham, G. R. (1980). Work redesign. Menlo Park, CA: Addison-Wesley.

Liden, R. C., \& Graen, G. B. (1980). Generalizability of the vertical dyad linkage model of leadership. Academy of Management Journal, 23, 451-465.

Madjar, N., Oldham, G. R., \& Pratt, M. G. (2002). There's no place like home? The contributions of work and nonwork creativity support to employees' creative performance. Academy of Management Journal, 45, 757767.

McCall, G., \& Simmons, J. L. (1978). Identities and interaction. New York: Free Press.

Mumford, M. D., \& Gustafson, S. B. (1988). Creativity syndrome: Integration, application, and innovation. Psychological Bulletin, 103, 27-43.

Munsterberg, H. (1913). Psychology and industrial efficiency. Boston, MA: Houghton-Mifflin.

Oldham, G. R., \& Cummings, A. (1996). Employee creativity: Personal and contextual factors at work. Academy of Management Journal, 39, 607-634.

Pellegrini, E. K., \& Scandura, T. A. (2008). Paternalistic leadership: A review and agenda for future research. Journal of Management, 34, 566-593.

Redding, S. G. (1990). The spirit of Chinese capitalism. New York: Water de Gruyter.

Riley, A., \& Burke, P. J. (1995). Identities and self-verification in the small group. Social Psychology Quarterly, 58, 61-73.

Scott, S. G., \& Bruce, R. A. (1994). Determinants of innovative behavior: A path model of individual innovation in the workplace. Academy of Management Journal, 37, 580-607.

Shalley, C. E., Zhou, J., \& Oldham, G. R. (2004). The effects of personal and contextual characteristics on creativity: Where should we go from here? Journal of Management, 30, 933-958.

Shin, S. J., \& Zhou, J. (2003). Transformational leadership, conservation, and creativity: Evidence from Korea. Academy of Management Journal, 46, 703-714.

Shin, S. J., \& Zhou, J. (2007). When is educational specialization heterogeneity related to creativity in research and development teams? Transformational leadership as a moderator. Journal of Applied Psychology, 92, 17091721.

Silin, R. H. (1976). Leadership and value: The organization of large-scale Taiwanese enterprises. Cambridge, MA: Harvard University Press. 
Spector, P. E. (1986). Perceived control by employees: A meta-analysis of studies concerning autonomy and participation at work. Human Relations, 39, 1005-1016.

Spreitzer, G. M. (1995). Psychological empowerment in the workplace: Construct definition, measurement, and validation. Academy of Management Journal, 38, 1442-1465.

Tierney, P., \& Farmer, S. M. (2002). Creative self-efficacy: Its potential antecedents and relationship to creative performance. Academy of Management Journal, 45, 1137-1148.

Tierney, P., Farmer, S. M., \& Graen, G. B. (1999). An examination of leadership and employee creativity: The relevance of traits and relationships. Personnel Psychology, 52, 591-620.

Weber, M. (1947). The theory of social and economic organization (A.M. Henderson \& T. Parsons, Trans.). New York: The Free Press.

Westwood, R. I. (1997). Harmony and patriarchy: The cultural basis for paternalistic headship among overseas Chinese. Organization Studies, 18, 445-480.

Westwood, R. I., \& Chan, A. (1992). Headship and leadership. In R. I. Westwood (Ed.), Organizational behavior: A Southeast Asian perspective (pp. 123-139). Hong Kong: Longman Group.

Williams, L. J., \& Anderson, S. E. (1994). An alternative approach to method effects by using latent-variable models: Applications in organizational behavior research. Journal of Applied Psychology, 79, 323-331.

Woodman, R. W., Sauyer, J. E., \& Griffin, R. W. (1993). Toward a theory of organizational creativity. Academy of Management Review, 18, 293-321.

Yang, C. F., \& Chiu, C. Y. (1987). The dilemma facing Chinese subjects in answering questionnaires: Reflecting on the over-reliance on Western rating scales in research. Chinese Journal of Psychology, 29, 59-78. (in Chinese).

Zhang, K., Song, L. J., Hackett, R. D., \& Bycio, P. (2006). Cultural boundry of expectancy theory based performance management: A commentary on DeNisi and Pritchard's performance improvement model. Management and Organization Review, 2, 279-294.

Zhou, J., \& George, J. M. (2001). When job dissatisfaction leads to creativity: Encouraging the expression of voice. Academy of Management Journal, 44, 682-696. 